\title{
Editorial
}

\section{Geomorphological Contribution to Flash Floods Hazard Evaluation: Examples from Campania (Southern Italy)}

\author{
Santangelo $\mathbf{N}^{*}$ \\ Dipartimento di scienze della Terra, dell'Ambiente e delle Risorse (DiSTAR), Università di Napoli Federico \\ II, Complesso Universitario Monte Sant'Angelo, Via Cinzia, Napoli, Italy
}

${ }^{*}$ Corresponding author: Santangelo N, Dipartimento di scienze della Terra, dell'Ambiente e delle Risorse (DiSTAR), Università di Napoli Federico II, Complesso Universitario Monte Sant'Angelo, Via Cinzia, Napoli, Italy, E-mail: nicsanta@unina.it

Received: 05 December, 2018; Accepted: 17 January, 2019; Published: 23 January, 2019

\begin{abstract}
This short note presents a review of some studies carried out in the last ten years in the region of Southern Apennines, facing the problem of flooding in small catchments and related piedmont areas. This kind of drainage basin are generally prone to flash flood events and many of them recorded in the last years serious damages. Unfortunately, they are often not monitored and the lack of information on rainfall and flow data makes more difficult to apply hydrological and hydraulic models to evaluate hazard and risk condition. In these contexts, a preliminary geomorphological study may be useful to identify the flooding prone areas and to depict the main flooding scenarios. This approach includes field surveys, morphometric analysis in GIS environment, air-photo interpretation and thematic mapping elaboration.
\end{abstract}

\section{Keywords}

flash flood, flooding scenarios, geomorphological analysis, Southern Italy

\section{Introduction}

A flash flood is a flood caused by heavy or excessive rainfall in a short period. This phenomenon is very frequent in Europe and in the Mediterranean area [1-5], where generally occurs in small catchments (few hundred square kilometres wide) with short response times (a few hours or less). These catchments often are not monitored and the lack of information on rainfall and flow data makes more difficult to apply hydrological and hydraulic models to evaluate hazard and risk condition. In this meaning, a geomorphological approach may be useful to identify the flooding prone areas and to depict the main flooding scenarios.
Along the Southern Apennines (Figure 1), drainage basins with high relief energy belonging to the category of small Mediterranean catchments, are a widespread geomorphic unit. These basins are generally characterized by low runoff rates, but during rainfall events of high intensity and short duration, mainly occurring during autumn and spring, may be subject to flash floods. The delivery areas of these basins are represented by piedmonts made up by single or coalescent alluvial fans (Figure 2A). During the last few centuries until now, these fans have been affected by severe flooding that had produced serious damage and loss of life. Cause to the relatively long-time lags between floods and the consequent loss of historical memory, development of urban areas in recent decades has not taken into account the presence of alluvial fans (Figure 2B). This great urban expansion implies that the local communities has to face with the problem of flash flood. This problem is getting worse taking into account the real increase in the frequency of violent convective storms in Mediterranean areas, producing rainfall patterns of high intensity within small space-time scales [6], which are critical for the initiation of flash floods.

During a flash flood, the sediments captured by the stream may be transported down valley according to different flow conditions and sediment concentrations, ranging from debris flow to water flood [7-9]. These phenomena may induce highly erosive flows and impact forces due to the mix of water, soil, boulders, trees and debris, but they also may have a very high rate of aggradation, due to the deposition of large particles. The identification of the specific hydro-geomorphic process is a central problem because each process has different intensity/magnitude (Figure 3). The impact of a debris flow is significantly higher than a water flood of the same volume and velocity, given the higher bulk density of the debris flow [10,11]. In this framework, the reconstruction of the potential flooding scenario may represent 
Citation: Santangelo N (2019) Geomorphological Contribution to Flash Floods Hazard Evaluation: Examples from Campania (Southern Italy). J Environ Sci Allied Res 2019: 44-50.

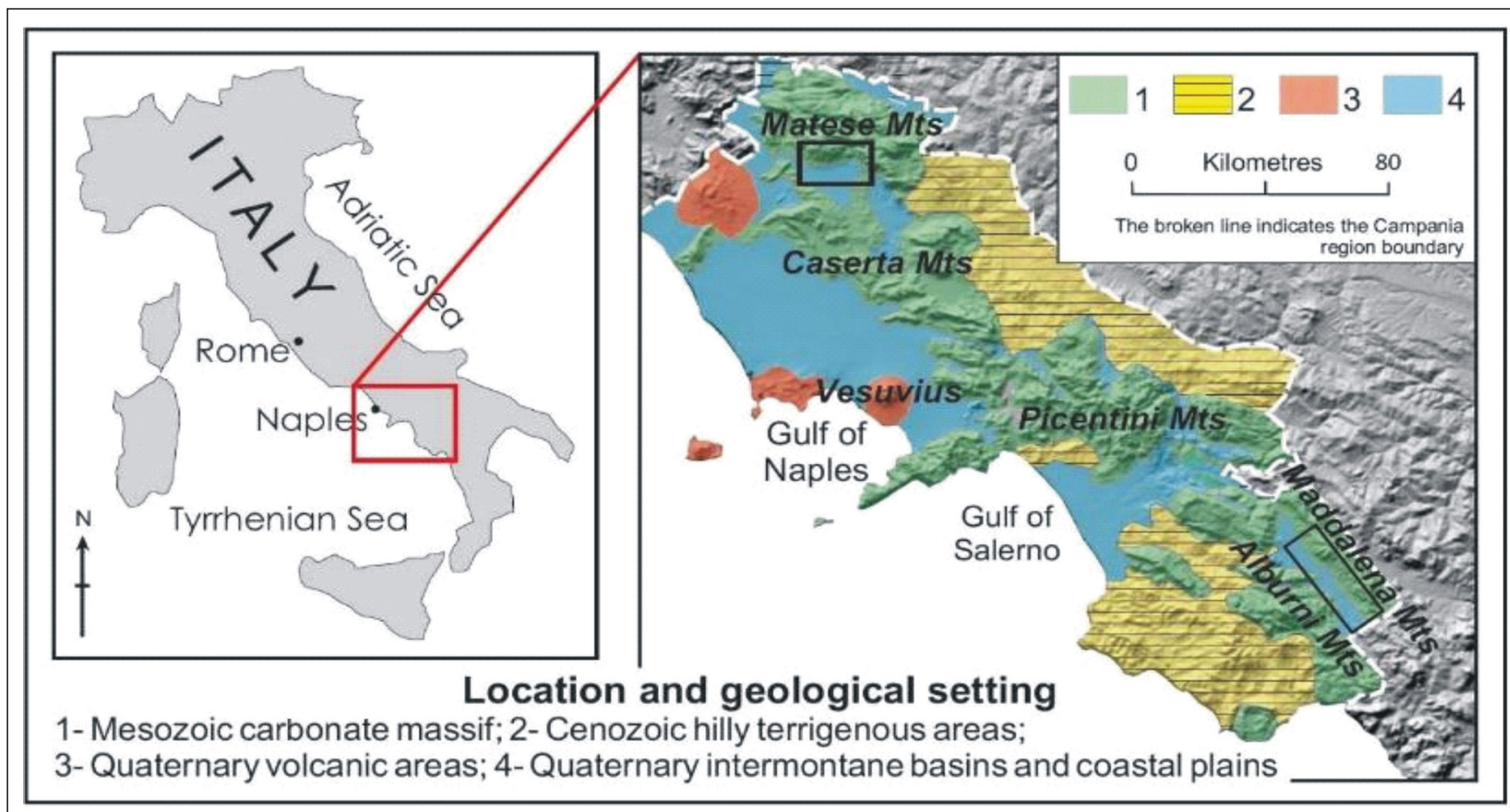

Figure 1: Location map and geological setting of the study area.

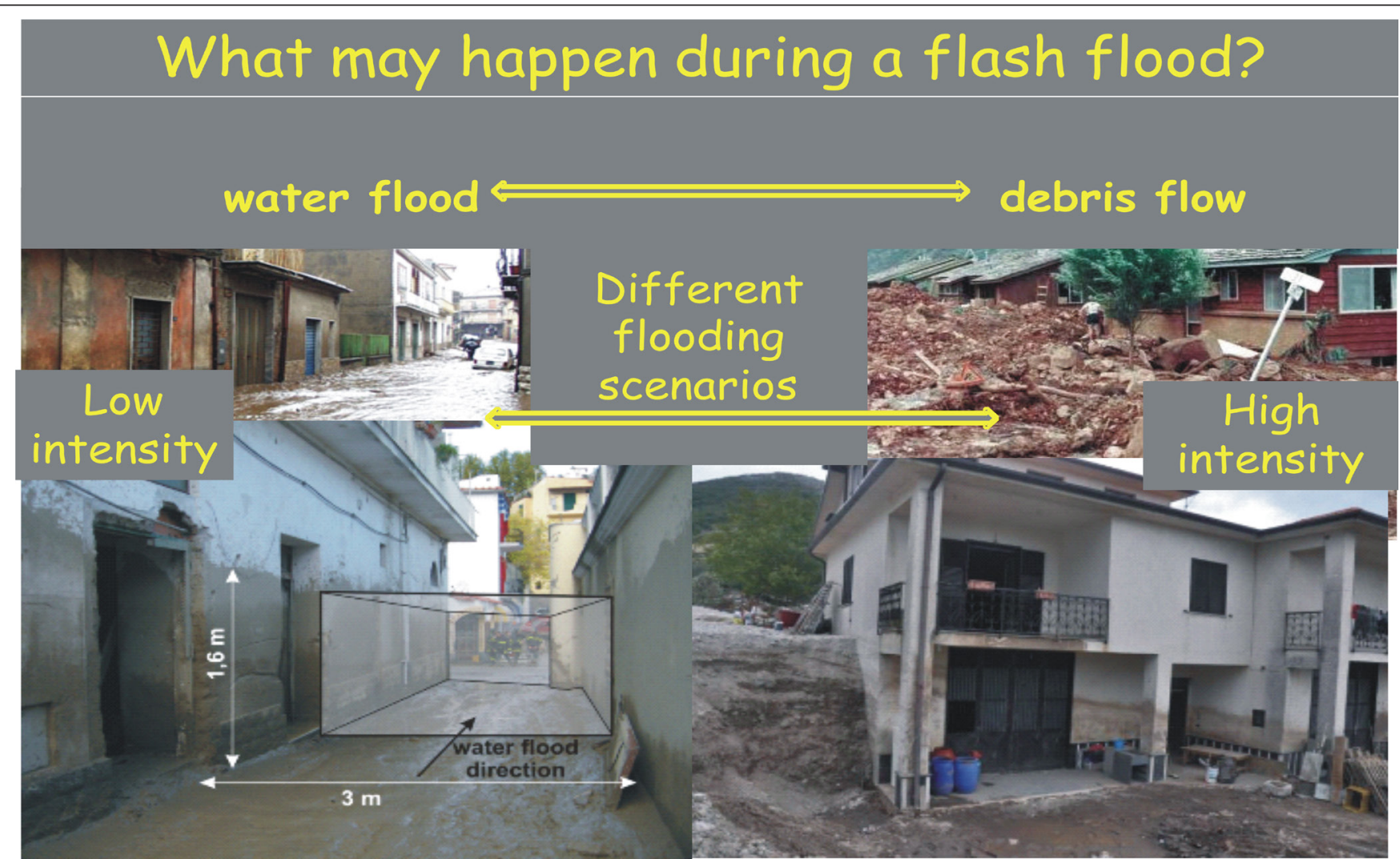

Figure 3: Examples of flooding scenarios. 

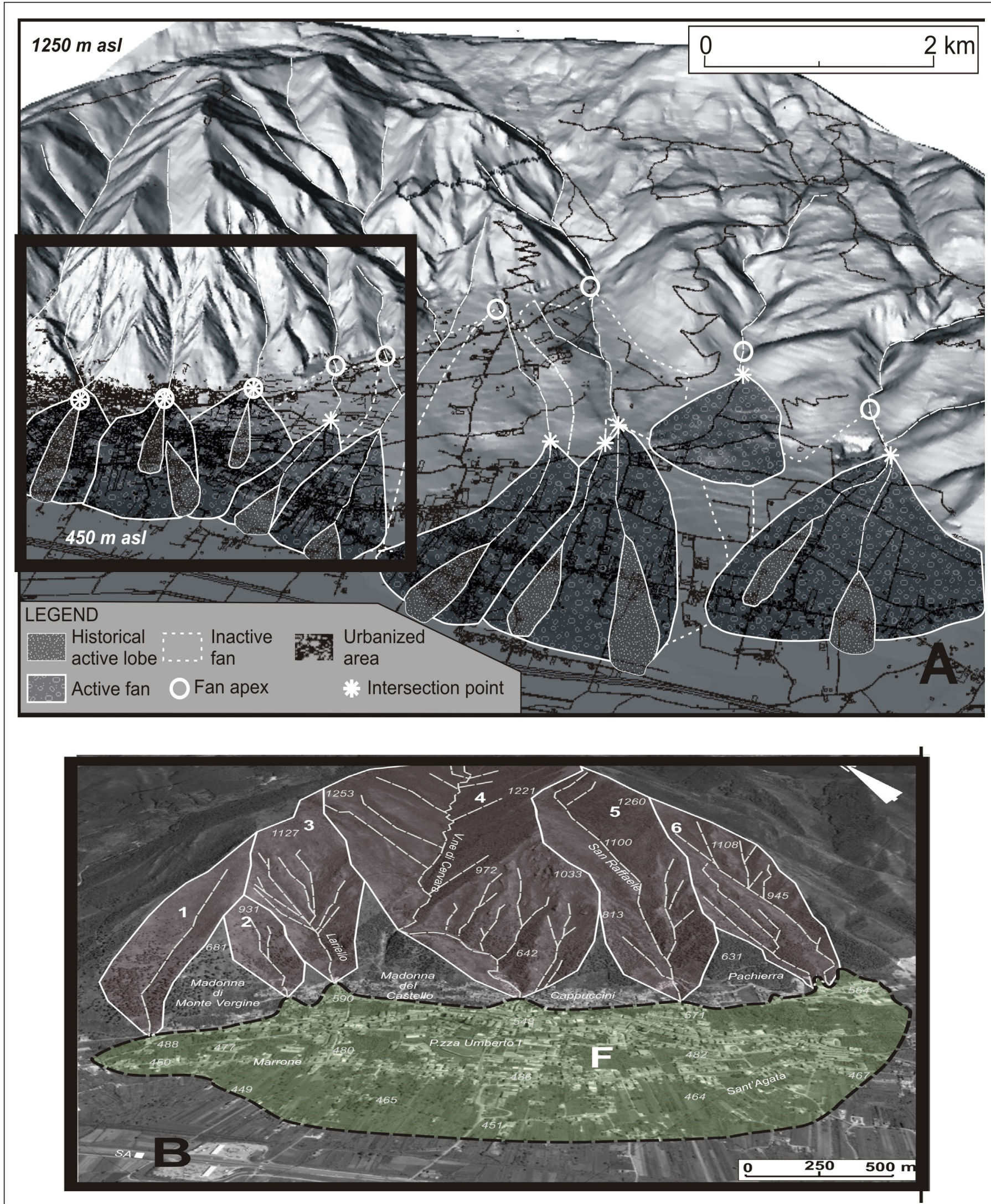

Figure 2: An Example of piedmont area (Maddalena Mts, Salerno province) and related geomorphological map; B detail of the urbanized portion of the piedmont (Sala Consilina town). From [14 and 20], modified. 


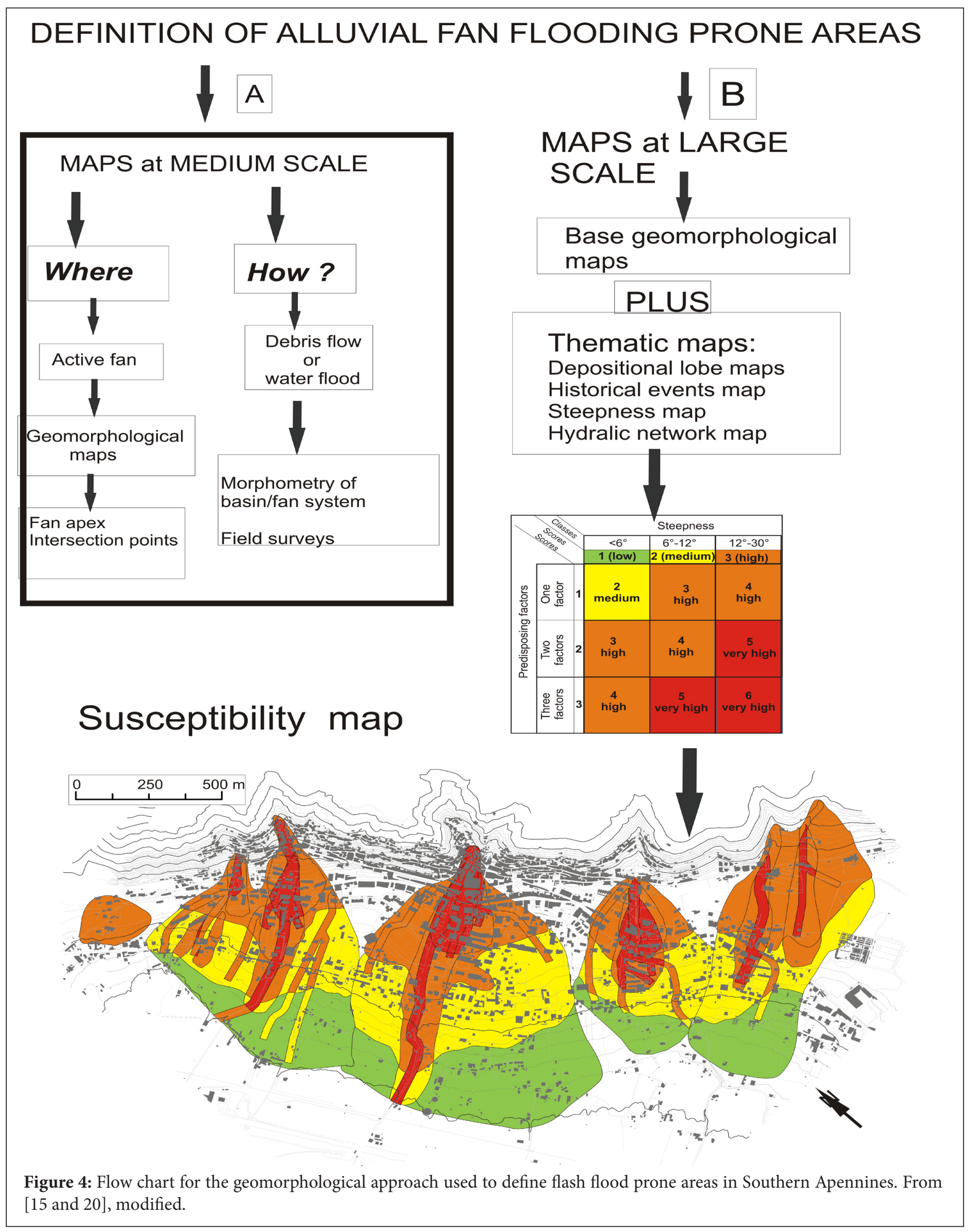


a significant contribution to studies aiming at risk evaluation and mitigation. This goal may be reached by means of geomorphological analysis at different scale including field surveys, morphometric analysis in GIS environment, air-photo interpretation and thematic mapping elaboration.

\section{Discussion}

Flash flood hazard can be defined as the probability that such event may occur in a precise place, on a precise moment and with a known intensity. This statement imply that hazard studies have to deal with three simple question: where, when and how a flash flood event may occur.

The contribution of geomorphological analysis may help in answering two of these questions: where could flooding occur and how severe it could be (Figure 4A).

As regard as the first question, current literature provides several approaches to this issue. According to the Federal Emergency Management Agency of the USA [8], detailed geomorphological mapping at small and medium scales (1:50000 - 1:10000) and integrated field surveys represent the best tools to identify the areas susceptible to flooding. It is based on the identification of the active portions of the fan (Special Flood Hazard Areas), which are those located down-fan in respect of the intersection point (Fig. $2 \mathrm{~A})[12,13]$. The geomorphological analysis carried out along the Southern Apennines chain [14,15] pointed out the presence of 102 basin/fan systems located in carbonate massifs that may be prone to flash flood events.

In order to give further information about the intensity of potential flooding (magnitude evaluation), many studies [16-19] have shown that relationships between morphometric attributes of alluvial fans and morphometric attributes of the corresponding upslope basins can be effectively exploited for classifying alluvial fans with respect to the two different dominant flooding mechanisms, i.e. either debris flows (Df) or water floods (Wf). In the case of the geological and geomorphological setting of Southern Apennines, the Authors [14] found out that the best discrimination between debris flow (Df) and water flood (Wf) processes is achieved by means of two related variables, one for the basin (feeder channel inclination, $\mathrm{Cg}$ ) and one for the fan (fan length, $\mathrm{Fl})$. A morphometric index of the alluvial fan ( Fx) can be derived by a linear equation applied to these two variables and may be easily used to identify the most critical situation at a regional scale. They also outlined that $48 \%$ of the Df fans and $20 \%$ of the Wf fans of the region is in coincidence with densely inhabited areas, thus envisaging the most potential high-risk situations.

Geomorphological analysis can be also carried out at larger scale (1:2,000 or higher, Figure 4B) especially in the case of extensively urbanized fan systems. This kind of approach entails detailed geological and geomorphological field surveys, historical data analysis on past floods and the reconstruction of the interaction between natural drainage directions and the urban infrastructures (main roads, buildings, bridges, etc). These points in fact, may represent critical conditions during flood propagation. In the case of the Sala Consilina town (Figure 4B), several thematic maps representing the main predisposing/critical factor for flood propagation were produced and then overlaid by means of a GIS procedure based on a susceptibility matrix [20,15]. The result was a flood susceptibility map representing different degrees of danger within the fan system.

The collection of a database on past flash floods is another significant step in study aiming at defining flash flood hazard. In the case of Southern Apennines, a data set of about 500 historical events from 1540 up to now, which is constantly updated [21] is available to the Author. These data have been useful to depict a regional scenario on the spatial and temporal distribution of flash floods in the region.

The reconstruction of flooding scenarios may also involve, when possible, detailed post-event surveys of recently occurred events $[22,23]$. In these cases, the acquisition of remotely sensed data by means of UAV (drones) represent and useful tools to obtain a lot of information regarding the real extent of the damaged area and the kind of erosional and depositional processes occurred during the flood. By coupling the field and remote sense information, it is possible to draw a detailed post-event geomorphological map, which can be very useful for the assessment of the real magnitude of the event. In the case of the Buccino event [22], occurred in 2011 in the Marzano Mts area, it was possible to assess the volumes of material transported down valley during the flash flood event. Collecting as more information as possible on recently occurred events may also be useful to perform back analysis in order to apply physical based model aiming at simulating future similar scenarios in different triggering conditions.

\section{Conclusive Remarks}

Geomorphological analysis may provide significant contribution in flash flood hazard studies.

More in detail, it can be useful in the following topics:

1. To identify the areas prone to this phenomenon (active portion of fan systems)

2. To analyse the basin/fan system by means of a morphometric approach aiming at distinguish between debris flow vs water flood dominated fans (collecting information about flood magnitude)

3. To study recently occurred events in order to better understand the extent of damaged areas and the kind of processes occurred.

These data may be employed for identifying the main hazard/risk scenarios. Collecting such data represents a fundamental tool for several studies, mainly aiming to define hydraulic models of flow propagation.

In particular these contributions can be useful to: 
Citation: Santangelo N (2019) Geomorphological Contribution to Flash Floods Hazard Evaluation: Examples from Campania (Southern Italy). J Environ Sci Allied Res 2019: 44-50.

1. Better understand the disaster processes and further improve flood prediction and hazard map

2. Plan monitoring, early warning and risk mitigation strategies

3. Test and calibrate hydraulic models

4. Enhance local and regional capacity to mitigate against such events in the future.

\section{References}

1. Borga M, Boscolo P, Zanon, F, Sangati M (2007) Hydrometeorological analysis of the August 29, 2003 flash flood in the eastern Italian Alps. J Hydrometeorol 8: 1049-1067.

2. Gaume E, Bain V, Bernardara P, Newinger O, Barbuc M, et al (2009) A compilation of data on European flash floods. J Hydrol 367: 70-78.

3. Marchi L, Borga M, Preciso E, Gaume E (2010) Characterisation of selected estreme flash floods in Europe and implications for flood risk management. J Hydrol 394: 118-133.

4. Tarolli P, Borga M, Morin E, Delrieu G (2012) Analysis of flash flood regimes in the North-Western and South-Eastern Mediterranean regions. Nat. Hazards Earth Syst 12: 1255-1265.

5. Merheb M, Moussa R, Abdallah C, Colin F, Perrin C, et al. (2016) Hydrological response characteristics of Mediterranean catchments at different time scales: a meta-analysis. Hydrolog Sci J 61: 25202539.

6. Romero R, Emanuel K (2013) Medicane risk in a changing climate. J Geophys Res: Atmos 118: 5992-6001.

7. Costa JE (1988) Rheologic, Geomorphic and Sedimentologic differentiation of water floods, hyperconcentrated flows, and debris flows. In Flood Geomorphology, Baker RR, Kochel RC, Patton C (eds). Wiley, New York, 113-122.

8. Fema (2000) Guidelines for determining flood hazards on alluvial fans. Federal Emergency Management Agency.

9. Jakob M (2005) Debris-flow hazard analysis. In: Jakob M, Hungr O (eds) Debris-flow Hazards and Related Phenomena. Praxis Springer, Berlin Heidelberg, 411-438.

10. Aulitzky H (1980) Preliminary two-fold classification of torrents. Proceedings International Symposium Interpraevent, Bad Ischl 4:285309.
11. Welsh A, Davies T (2011) Identification of alluvial fans susceptible to debris flow hazards. Landslides 8: 183-194.

12. Hooke RL (1967) Processes on arid region alluvial fans. J Geol 75: 438-460.

13. Blair TC, McPherson JG (1994) Alluvial fan processes and forms. In: Geomorphology of desert environments, Abrahams AT, Parsons AJ (eds). Chapman and Hall: London, 354-402.

14. Santangelo N, Daunis-i-Estadella J, Di Crescenzo G, Di Donato V, Faillace P, et al. (2012) Topographic predictors of susceptibility to alluvial fan flooding, Southern Apennines. Earth Surf Proc Land 37: 803-817.

15. Scorpio V, Santangelo N, Santo A (2016) Multiscale map analysis in alluvial fan flood-prone areas. J Maps 12: 382-393.

16. Kostaschuk RA, MacDonald GM, Putman PE (1986) Depositional processes and alluvial fan-drainage basin morphometric relationship near Banff, Alberta, Canada. Earth Surf Proc Land 11: 471 484.

17. De Scally FA, Owens IF, Louis J (2010) Controls on fan depositional processes in the schist ranges of the Southern Alps, New Zealand, and implications for debris-flow hazard assessment. Geomorphology 122: 99-116.

18. Crosta GB, Frattini P (2004) Controls on modern Alluvial fan processes in the Central Alps, Nothern Italy. Earth Surf Proc Land 29: 267-293.

19. De Scally FA, Owens IF (2004) Morphometric controls and Geomorphic responses on fans in the Southern Alps, New Zealand. Earth Surf Proc Land 29: 311-322.

20. Santangelo N, Santo A, Di Crescenzo G, Foscari G, Liuzza V, et al. (2011) Floodsusceptibility assessment in a highly urbanized alluvial fan: the case of Sala Consilina (southern Italy). Nat Hazards Earth Syst Sci 11: 2765-2782.

21. Vennari C, Santangelo N, Parise M and Santo A (2016) A database on flash flood events in Campania, southern Italy, with an evaluation of their spatial and temporal distribution. Nat. Hazards Earth Syst Sci 16: 2485-2500.

22. Santo A, Santangelo N, Di Crescenzo G, Scorpio V, De Falco M, et al. (2015) Flash flood occurence and magnitude assessment in an alluvial fan context: the October 201I event in the Southern Apennines. Nat Hazards 78: 417-442.

23. Santo A, Santangelo N, Forte G, De Falco M (2016) Post flash flood survey: the October 14th and 15th 2015 event in the Paupisi- Solopaca area (Southern Italy). J Maps 13: 19-25. 


\section{NSC \\ NOR RCR R R}

submit your manuscripts at

www. norcaloa.com 